\title{
CAUSAS E EFEITOS DA EXPRESSÃO DE \\ COMPETÊNCIAS NO TRABALHO: PARA ENTENDER \\ MELHOR A NOÇÃO DE COMPETÊNCIA
}

\section{CAUSES AND CONSEQUENCES OF THE EXPRESSION OF COMPETENCES AT WORK: UNDERSTANDING THE COMPETENCE CONCEPT}

\section{HUGO PEINA BRANDÃO}

Doutorando em Psicologia Social e do Trabalho e mestre em Administração pela Universidade de Brasília (UnB). Pesquisador master da Universidade Corporativa Banco do Brasil, professor da pós-graduação lato sensu da Fundação Getulio Vargas e do Centro Universitário do Distrito Federal (UniDF), palestrante e consultor. SMDB Conjunto 12-B, lote 3, casa C, Lago Sul - Brasília - DF - CEP 71680-020 E-mail: hugopb@tba.com.br

\section{JAIRO EDUARDO BORGES-ANDRADE}

Ph.D. e M.Sc. em Sistemas Instrucionais pela Florida State University (EUA). Professor titular do Departamento de Psicologia Social e do Trabalho da Universidade de Brasília (UnB), nos cursos de graduação, mestrado e doutorado em Psicologia, consultor e pesquisador 1-A no CNPq.

SQN 106, Bloco I, ap. 605, Asa Norte - Brasília - DF - CEP 70742-090 E-mail: jeborges@linkexpress.com.br 


\section{RESUMO}

A noção de competência caracteriza-se como complexa e multifacetada,podendo ser interpretada de diferentes maneiras. Este ensaio tem como objetivo discutir a natureza da competência humana e os principais fatores que explicam a sua expressão no trabalho,à luz de abordagens cognitivistas,como aquelas relacionadas à atribuição de causa,ao estudo das relações entre atitude e comportamento e à aprendizagem nas organizações. São apresentadas semelhanças e relações entre conceitos e proposições oriundos de diferentes correntes,buscando compreender as causas e consequiências da competência. Discute-se também a influência da aprendizagem e do suporte organizacional sobre o desenvolvimento e a mobilização de competências no trabalho. Embora esse conceito tenha emergido na área de Administração,algumas teorias, pesquisas e proposições de outras áreas de conhecimento,como a Psicologia Social e Organizacional,ajudam a interpretar e a compreender a natureza da competência e de seus componentes. Tratando-se de estudo sobre um conceito em evidência e cujos pressupostos ainda carecem de investigações empíricas,ao final é sugerida uma agenda de pesquisa.

\section{PALAVRAS-CHAVE}

Competência; Desempenho profissional; Comportamento no trabalho; Aprendizagem; Suporte organizacional.

\section{ABSTRACT}

Competence is a complex and multifaceted concept,which may assume different meanings. The objective of this paper is to discuss the nature of the human competence and the main factors that explain its expression atwork, based on the framework of cognitive approaches as those related to the attribution of cause, the study of the relations between attitude and behavior and learning in organizations. Similarities and relationshi ps between concepts and proposals from 
differenttheoretical approaches are presented,in order to understand the causes and consequences of competence. The influence of learning and organizational supporton the developmentand the mobilization of competences is also discussed. Even thoughtthis concepthas emerged in the Business Administration area,some theories,studies and proposals from others areas of knowledge, as Social and Organizational Psychology,may help to interpretand to understand the nature of the human competence and its components. Since the study aboutthis concept is in evidence and its theoretical supportstill needs empirical inquiry,a research agenda is suggested atthe end of the paper.

\section{KEYWORDS}

Competence; Performance; Behavior atwork; Learning; Organizational support.

\section{INTRODUÇÃO}

No contexto de transformações sociais,econômicas e culturais por que passa a sociedade contemporânea,o ambiente organizacional tem procurado desenvolver e incorporar inovações,sejam elas em produtos,processos produtivos ou modelos de gestão,que lhes permitam melhorar continuamente seu desempenho.

A gestão por competências ${ }^{1}$ (CARBONE etal.,2005; HEENE; SANCHEZ, I997; LE BOTERF,I999; ZARIFIAN,I999) se insere entre os modelos gerenciais propostos para aprimorar os desempenhos profissional e organizacional. Baseando-se no pressuposto de que o domínio de certos recursos é determinante do desempenho de uma organização,esse modelo propõe-se a integrar e orientar esforços,sobretudo os relacionados à gestão de pessoas, visando desenvolver e sustentar competências consideradas fundamentais à consecução dos objetivos organizacionais (BRANDÃO; GUIMARÃES,2002; BITENCOURT,2004).

Com a emergência da gestão por competências (GONCZI,I999), grande discussão tem sido feita em torno do conceito de competência,suas dimensões e

Embora neste ensaio se utilize a expressão "gestão por competências" para denominar esse modelo de gestão,muitos autores adotam denominações diferentes para expressar concepções semelhantes. É comum na literatura sobre o assunto a utilização de termos como "gestão de competências", "gestão baseada em competências" e "gestão de pessoas por competências", entre outros,que,apesar das diferenças semânticas,representam essencialmente a mesma idéia. Neste ensaio,optou-se por utilizar a denominação "gestão por competências" porque a partícula "por",quando utilizada na formação de adjuntos,indica fim, propósito,destino,desejo. Assim,a expressão "gestão por competências" inspira a idéia de que o esforço gerencial tem como propósito alavancar,desenvolver,mobilizar competências,conforme sugerido por Le Boterf (1999) e Carbone etal. (2005). 
implicações. Por isso,a expressão "competências" adquiriu variadas conotações no campo da gestão organizacional,sendo analisada e utilizada de diferentes maneiras,conforme relatam McLagan (I997) e Brandão e Guimarães (2002),o que parece contribuir para a fragmentação teórica nesse campo de estudo.

No entanto,algumas teorias e pesquisas no campo da Psicologia Social e Organizacional,sobretudo aquelas relacionadas à cognição social e a abordagens instrucionais,ao serem cotejadas com proposições oriundas da área de Administração,podem auxiliar a esclarecer a natureza da competência e seus elementos constitutivos. É o que sugere Bastos (2004), para quem as abordagens cognitivistas podem ser largamente utilizadas para analisar e explicar fenômenos e processos organizacionais.

Dessa forma,constitui objetivo deste ensaio discutir pressupostos e componentes da noção de competência,assim como os principais fatores que explicam a sua expressão no trabalho,à luz de abordagens cognitivistas,como aquelas relacionadas à atribuição de causa (HEIDER,I958), ao estudo das relações entre atitude e comportamento (MARTIN-BARÓ,I985) e à aprendizagem nas organizações (GONCZI,I999). Pretende-se,também,apresentar semelhanças e relações entre conceitos e proposições das áreas de Psicologia Social e Organizacional e de Administração,buscando compreender as causas e os efeitos da competência. Ao final,discute-se a influência da aprendizagem e do suporte organizacional sobre o desenvolvimento e a expressão de competências no trabalho.

\section{NOÇÃO DE COMPETÊNCIA}

No final da Idade Média,o termo competência pertencia essencialmente à linguagem jurídica. Dizia respeito à faculdade atribuída a uma pessoa ou a uma instituição,para apreciar e julgar certas questões. Por extensão,o termo veio a designar o reconhecimento social sobre a capacidade de alguém pronunciar-se a respeito de determinado assunto e,mais tarde,passou a ser utilizado também para qualificar o indivíduo capaz de realizar certo trabalho (ISAMBERT-JAMATI, I997; BRANDÃO; GUIMARÃES,2002).

Com a Revolução Industrial e o advento do taylor-fordismo, o termo competência foi incorporado à linguagem organizacional,sendo utilizado para qualificar a pessoa capaz de desempenhar eficientemente determinado papel. A partir da década de 1970,o interesse pelo assunto estimulou o debate teórico e a realização de pesquisas. Muitos autores procuraram criar definições próprias para o termo,chamando a atenção para variados aspectos da competência. Gilbert (1978), autor da área de Psicologia Organizacional,por exemplo,destaca que a competência é expressa em razão do desempenho ou comportamento da pessoa 
no trabalho,enquanto Durand (2000),da área de Administração,dá ênfase aos elementos que constituem a competência,ou seja,aos conhecimentos, às habilidades e às atitudes da pessoa.

Por trás da proposta de Gilbert(I978),está expressa a base teórica influenciada pelo "movimento S-R", que na psicologia advoga que a compreensão do comportamento deve estar vinculada à investigação das relações estabelecidas entre estímulos (S) e respostas (R). A proposta de Durand (2000),por sua vez, parece influenciada pelo "movimento S-O-R", pois parte da premissa de que essas relações,para serem plenamente compreendidas,precisam levar em conta o que ocorre no indivíduo ou organismo $(\mathrm{O})$,que mediaria as relações entre estímulos (S) e respostas (R). Esse segundo movimento,em psicologia,constitui a base sobre a qual estão sustentadas as abordagens cognitivistas e pressupõe que a interação do indivíduo com o ambiente resulta em processos cognitivos ou na aquisição de conhecimentos,habilidade e atitudes.

Não obstante a possibilidade de interpretar a competência de múltiplas maneiras,é possível perceber a existência de duas grandes correntes teóricas, conforme sugere Dutra (2004). A primeira,representada princi palmente por autores norte-americanos (BOYATZIS,I982; MCCLELLAND, I973, por exemplo),entende a competência como um conjunto de qualificações ou características subjacentes à pessoa,que permitem que ela realize determinado trabalho ou lide com uma dada situação. A segunda,representada sobretudo por autores franceses (LE BOTERF,I999; ZARIFIAN,I999, por exemplo), associa a competência não a um conjunto de atributos da pessoa,mas sim às suas realizações em determinado contexto,ou seja,àquilo que o indivíduo produz ou realiza no trabalho (DUTRA,2004).

Nos últimos anos,uma terceira vertente tem obtido destaque à medida que busca adotar uma perspectiva integradora,procurando definir a competência a partir da junção de concepções das referidas correntes. Esse posicionamento é defendido por Gonczi (I999), para quem a competência associa atributos pessoais ao contexto em que são utilizados, isto é,ao desempenho da pessoa no trabalho. A competência é entendida,então,não apenas como um conjunto de conhecimentos, habilidades e atitudes necessários para exercer certa atividade, mas também como o desempenho expresso pela pessoa em determinado contexto,em termos de comportamentos adotados no trabalho e realizações decorrentes.

Sob essa perspectiva,evidentemente mais próxima do denominado "movimento S-O-R" e, portanto, de abordagens cognitivistas, competências podem ser entendidas como combinações sinérgicas de conhecimentos, habilidades e atitudes, expressas pelo desempenho profissional dentro de determinado contexto organizacional,que agregam valor a pessoas e organizações (FREITAS; 
BRANDÃO, 2005). Essas combinações representariam a letra "O”, que sugere ser o indivíduo capaz de desenvolver competências que medeiam as relações que seu comportamento (R) estabelece com o ambiente (S). Segundo Carbone etal. (2005), definições como essa parecem possuir aceitação mais ampla,tanto no meio acadêmico quanto no ambiente organizacional,na medida em que consideram as diversas dimensões do trabalho (cognitiva,psicomotora e afetiva) e associam a competência ao desempenho,dentro de um contexto ou no âmbito de uma estratégia organizacional.

As competências humanas ${ }^{2}$, então, são reveladas quando as pessoas agem ante as situações profissionais com as quais deparam (ZARIFIAN,I999). Servem como ligação entre as condutas individuais e a estratégia da organização (PRAHALAD; HAMEL, I990). Assim, agregam valor, econômico ou social, a indivíduos e organizações,posto que contribuem para a consecução de objetivos organizacionais e expressam o reconhecimento social sobre a capacidade das pessoas,equi pes e organizações,conforme ilustra a Figura I.

\section{FIgURA I}

\section{COMPONENTES DA COMPETÊNCIA HUMANA}

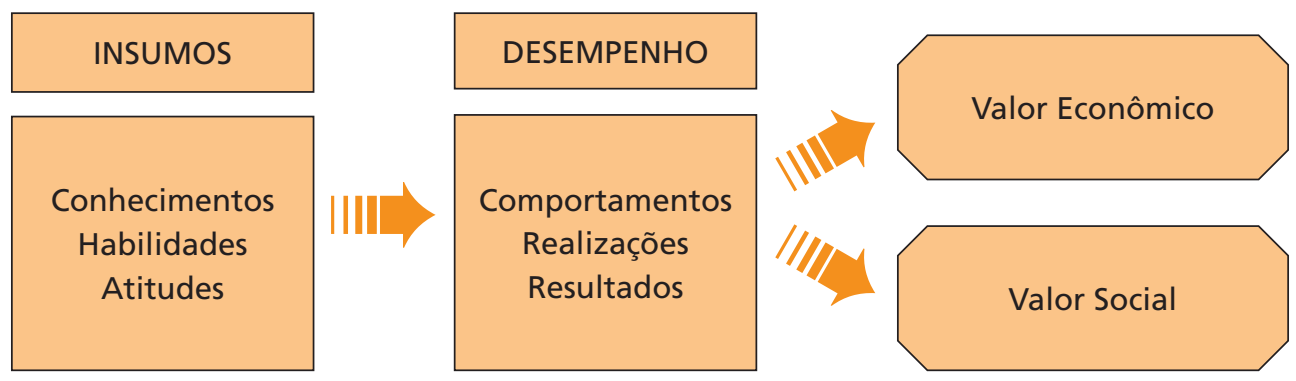

Fonte: Fleury e Fleury (200I) e Dutra (2004),com adaptações.

Essa figura,além de sugerir a complementaridade de conhecimentos,habilidades e atitudes,mostra que a aplicação desses três elementos no trabalho gera um desempenho profissional (GONCZI,I999; DURAND,2000). Esse desempenho,por sua vez,é expresso pelos comportamentos que a pessoa manifesta no trabalho e pelas conseqüências desses comportamentos,em termos de realizações

Alguns autores (HEENE; SANCHEZ,I997; BRANDÃO; GUIMARÃES,2002,por exemplo) classificam as competências como humanas ou profissionais (aquelas relativas a indivíduos) e como organizacionais (aquelas que constituem atributos da organização,e não de indivíduos isoladamente). Este ensaio trata apenas da competência no nível individual,como um atributo da pessoa. 
ou resultados (GILBERT,I978), de tal forma que o desempenho competente possui valor tanto para a pessoa que o produz quanto para a organização em que ela trabalha.

A competência constitui,portanto,um conceito complexo e multifacetado, que pode ser analisado sob diferentes perspectivas. Algumas teorias e pesquisas advindas da Psicologia Social e Organizacional,no entanto,podem ajudar a compreender os vários elementos que compõem esse conceito e as relações existentes entre eles,o que será discutido a seguir.

\section{CAUSAS E EFEITOS DA COMPETÊNCIA}

Alguns estudos e teorias da área de Psicologia Social e Organizacional buscam utilizar o conhecimento sobre os elementos constitutivos de uma ação para interpretá-la ou predizê-la,isto é,procuram avaliar o papel de fatores que contribuem para um comportamento ou resultado. Sobre isso,Vonk (I998) esclarece que,para fazer inferências sobre o comportamento de uma pessoa,é preciso ana lisar as possíveis causas desse comportamento,e Bandura (i969) explica que a ação realizada pelo indivíduo pode ser determinada tanto por condições ou estímulos externos quanto por fatores intrínsecos ao sujeito. Como o comportamento no trabalho e suas conseqüências (realizações ou resultados) expressam a competência profissional (DURAND,2000), então tais estudos podem ajudar a compreender o conceito e a natureza da competência.

Heider (I958) desenvolveu diversos estudos a respeito do comportamento interpessoal,procurando analisar o processo de determinar ou inferir a razão pela qual um comportamento ocorre. Seus estudos influenciaram numerosos pesquisadores e pensadores, dando origem à denominada Teoria da Atribuição de Causa. Essa teoria sugere que as pessoas atribuem,ao comportamento dos outros, dois ti pos de causas: internas ou disposicionais (quando a causalidade é atribuída a fatores internos da pessoa) e externas ou situacionais (quando a causalidade é atribuída a fatores externos),conforme explicam Davis e Newstrom (I992). Assim,quando alguém está atrasado para uma reunião de trabalho, pode-se atribuir o atraso da pessoa a fatores internos,como a indiferença dela, por exemplo,ou a fatores externos que a impossibilitaram de chegar a tempo (VONK,I998),como o trânsito ou um defeito em seu veículo,por exemplo. A noção de causa,portanto,em termos gerais,está associada à idéia de "agente" ou "força", ou seja,ao pressuposto de que existem fatores que causam ou determinam certos eventos (efeitos). Sob essa perspectiva,a causalidade revela-se,então, quando o evento conseqüente sucede, no tempo, de forma consistente, o fator antecedente. 
Segundo Heider (1958), o resultado de uma ação depende de aspectos disposicionais e situacionais. Os primeiros referem-se a propriedades (como a capacidade, por exemplo) que dispõem as pessoas, sob certas condições, a se comportarem de determinada maneira. Os últimos, por sua vez, dizem respeito a propriedades mais variáveis, presentes no ambiente,que influenciam a coordenação entre o resultado e as propriedades disposicionais do indivíduo, visto que podem aumentar ou reduzir a possibilidade de a pessoa manifestar suas capacidades.

Heider (I958) explica,ainda,que a disposição da pessoa para a ação pode ser determinada por dois elementos: um fator de poder (capacidade) e um fator motivacional. A capacidade é condicionada por conhecimentos e habilidades que tornam a pessoa capaz de realizar algo. O fator motivacional,por sua vez,referese àquilo que a pessoa tenta fazer (sua intenção) e à intensidade com que tenta fazê-lo (seu esforço). Manifesta-se na tentativa,impulsionando e orientando a ação,além de dar-lhe caráter intencional (HEIDER,I958). Para Atkinson (apud MCCLELLAND,I985),o fator motivacional constitui aquilo que influencia a tendência de uma pessoa adotar certo comportamento. A motivação,para ele,equivale à determinação do indivíduo na busca por um objetivo.

Capacidade e motivação são fatores necessários para determinar a ação,mas nenhum deles,isoladamente, é suficiente. Heider (1958) explica que,se uma pessoa tem capacidade,mas não tem motivação,ou vice-versa,não fará progresso na direção do objetivo. Os fatores "ser capaz" e "desejar" são vistos por esse autor como condições para a ação que obteve êxito.

Nesse sentido, parece que conhecimentos, habilidades e atitudes, os três elementos constitutivos da competência,podem ser considerados propriedades disposicionais da pessoa,isto é,causas do desempenho ou da expressão de competências no trabalho. É importante,então,analisar cada um desses elementos e as relações entre eles.

De acordo com Durand (2000), o conhecimento corresponde a uma série de informações assimiladas e estruturadas pelo indivíduo,que lhe permitem "entender o mundo". Refere-se ao saber que a pessoa acumulou ao longo da vida. Davise Botkin (I994) e Davenporte Prusak (I998) explicam que o conhecimento deriva da informação,que,por sua vez,deriva de conjuntos de dados. Segundo esses autores, dados são séries de fatos ou eventos isolados; informações são dados que,percebidos pelo indivíduo,têm significado e relevância; e conhecimentos são conjuntos de informações, reconhecidas e integradas pela pessoa em um esquema cognitivo preexistente,que causam impacto sobre seu julgamento ou comportamento. Para Bloom etal. (I979) e Gagné etal. (I988),autores de teorias instrucionais,o conhecimento representa algo relacionado à lembrança de idéias ou fenômenos,isto é,algo armazenado na memória da pessoa por meio de processos psicológicos de aquisição e interpretação de informações. 
A habilidade,por sua vez,refere-se ao saber como fazer algo (GAGNÉ etal., I988) ou à capacidade da pessoa de fazer uso produtivo do conhecimento,ou seja,de instaurar conhecimentos armazenados em sua memória e utilizá-los em uma ação (DURAND,2000). Essa dimensão está relacionada à capacidade de processamento cognitivo,ou seja,à capacidade de processar informações (como relacionar idéias,reorganizar esquemas e derivar implicações lógicas a partir de regras gerais) para resolver problemas ou para lidar com determinada situação (PRIMI etal.,200I).

Segundo Bloom etal. (I979),uma definição comum sobre habilidade é a de que o indivíduo pode buscar,em suas experiências anteriores,conhecimentos (de fatos ou princípios) e técnicas apropriadas para examinar e solucionar um problema qualquer. As habilidades podem ser classificadas como intelectuais, quando abrangerem essencialmente processos mentais de organização e reorganização de informações - como na realização de uma operação matemática, por exemplo - e como motoras ou manipulativas, quando exigirem fundamentalmente uma coordenação neuromuscular (BLOOM etal.,I979; GAGNÉ etal., I988), como na colocação de peças em uma linha de produção, por exemplo. Uma investigação realizada por McClelland (I985) aponta a habilidade como um importante preditor do desempenho. Segundo esse estudo,a combinação da habilidade com os motivos da pessoa e fatores situacionais favoráveis explica grande parte do comportamento no trabalho.

Ao abordar esses dois primeiros elementos ou dimensões da competência (conhecimentos e habilidades),Durand (2000) utiliza a estrutura de análise do conhecimento sugerida por Sanchez (I997),explicando que habilidade refere-se ao saber como fazer algo em determinado processo (know-how), enquanto conhecimento diz respeito ao saber o que e por que fazer (know-what e know-why),ou seja, à compreensão do princípio teórico que rege esse processo e seu propósito. A associação de conhecimentos e habilidades,então,parece constituir o que Heider (I958) e outros teóricos da atribuição de causa denominam capacidade,conforme já descrito. Esses elementos, portanto,são propriedades disposicionais,visto que dispõem as pessoas a se comportarem de determinada maneira.

A atitude,como terceiro elemento ou dimensão da competência,refere-se a aspectos sociais e afetivos relacionados ao trabalho (DURAND,2000). Embora algumas investigações não tenham conseguido verificar empiricamente as relações entre a atitude e o comportamento,sobretudo por dificuldades metodológicas (MARTIN-BARÓ,I985), a atitude é tida conceitualmente como uma propriedade que influencia,em certa medida,o comportamento da pessoa. Sob essa perspectiva,Gagné etal. (I988) comentam que atitudes são estados complexos do ser humano,que afetam o seu comportamento em relação a pessoas,objetos e eventos,determinando a escolha de um curso de ação pessoal. Segundo esses 
autores,as pessoas têm preferências por alguns ti pos de atividades e mostram interesse por certos eventos mais que por outros. O efeito da atitude é justamente ampliar a reação positiva ou negativa de uma pessoa,ou seja,sua predisposição ou intenção,em relação à adoção de uma ação específica.

Esse componente da competência está relacionado a um sentimento ou a um grau de aceitação ou rejeição da pessoa em relação aos outros,a objetos ou a situações. A atitude, então, por analogia,refere-se ao que Heider (I958) denominou "desejar" e ao que Durand (2000) referiu-se como "querer fazer". Sansone (i986) entende a atitude como um componente da motivação intrínseca - aquela relacionada ao desejo, à disposição ou à satisfação pessoal do indivíduo pelo trabalho que realiza -,e estudos de McClelland (I985) apontam a motivação como um importante preditor do comportamento no trabalho. A atitude parece constituir o que Heider (I958) denominou fator motivacional, visto que influencia a tendência de a pessoa adotar determinado comportamento. Caracteriza-se,portanto,como uma outra propriedade disposicional do indivíduo.

Algumas pesquisas indicam que esses três elementos determinantes da competência (conhecimentos, habilidades e atitudes) possuem caráter complementar e interdependente,de forma que existe uma influência mútua entre eles. Um estudo realizado por Sansone (I986), por exemplo,indicou que o conhecimento da pessoa a respeito dos padrões de competência requeridos em seu trabalho afetava não apenas a percepção dela sobre sua competência (auto-eficácia), mas também a sua disposição (ou seja,suas atitudes) para demonstrar as competências requeridas. Um experimento realizado por Harackiewicz etal. (I985) também indicou que conhecimentos adquiridos pelos sujeitos antes de uma atividade afetaram positivamente a sua auto-eficácia e o seu interesse pelo trabalho. Da mesma forma,o interesse da pessoa pelo trabalho influencia a aprendizagem de novos conhecimentos e habilidades (POZO,2002), e uma habilidade pressupõe o conhecimento de técnicas ou princípios (BRANDÃO etal.,200I).

Diante do exposto,é possível afirmar que conhecimentos, habilidades e atitudes seriam propriedades disposicionais do indivíduo,constituindo causas de seus desempenhos ou da expressão de competências. Sabe-se também que as pessoas manifestam suas capacidades e seus motivos por meio da realização (HEIDER,I958),ao transformarem a capacidade potencial em ação real,de tal forma que a competência profissional é expressa pelos comportamentos que a pessoa adota no trabalho e pelos resultados decorrentes (CARBONE etal.,2005). Estes, por sua vez,têm como conseqüência a geração de valor,econômico ou social,tanto para a pessoa quanto para a organização em que ela atua,conforme já explicado.

Embora os modelos de atribuição de causa sejam por definição relacionados ao estudo das causas do comportamento (VONK, I998), e não às suas conse- 
qüências,estas não se fazem menos importantes para compreender a noção e a natureza da competência. Em estudo realizado por Harackiewicz etal. (I985), por exemplo,verificou-se que o valor percebido ou atribuído pelas pessoas à expressão de suas competências pode fazer que se dediquem mais e se tornem mais envolvidas com o trabalho que realizam. Assim,o valor que um comportamento agrega à pessoa que o adota torna-se conseqüência e também causa da competência,na medida em que influencia as propriedades disposicionais do indivíduo.

Reeder etal. (2004),por sua vez,verificaram que comportamentos atribuídos a propriedades disposicionais da pessoa são mais valorizados (considerados mais importantes) que aqueles atribuídos a fatores situacionais. Em outros estudos, Vonk (I998) e Vonk e Konst (2003), ao investigarem as relações entre o comportamento e a percepção social,verificaram que as conseqüências do comportamento de uma pessoa podem influenciar o julgamento dos outros a respeito dela. Segundo Vonk (1998),quando o comportamento de uma pessoa tem uma conseqüência negativa para aquele que o julga ou avalia,então as inferências correspondentes são mais extremadas e negativas, especialmente se o comportamento é causado por fatores disposicionais do sujeito. Tais resultados trazem implicações importantes para os modelos de avaliação do desempenho humano no trabalho em que a avaliação é baseada na percepção das pessoas sobre as competências expressas pelo indivíduo avaliado.

Considerando a necessidade de aperfeiçoar continuamente seu desempenho, as organizações estão impelidas à adoção de iniciativas que possam favorecer a expressão de competências desejadas no trabalho. Para tanto,podem-se promover processos de aprendizagem para desenvolvimento de competências e, ainda,atuar sobre componentes situacionais,criando oportunidades favoráveis à manifestação de competências e afastando barreiras ambientais,questões que serão discutidas a seguir.

\section{O papel da Aprendizagem E DO SUPORTE ORGANIZACIONAL}

A aprendizagem constitui o processo ou meio pelo qual se adquire a competência,enquanto o desempenho no trabalho representa uma manifestação do que o indivíduo aprendeu,da competência por ele adquirida em processos de aprendizagem (FREITAS; BRANDÃO,2005). Desenvolver novas formas para prover oportunidades e experiências de aprendizagem constitui, portanto,um grande desafio para as organizações (CASEY,I999),sobretudo porque a complexidade do ambiente organizacional faz surgir diversificadas demandas de apren- 
dizagem,aumentando a distância entre o que as pessoas sabem e o que elas precisam aprender (POZO,2002).

Aprender implica mudar conhecimentos, habilidades ou atitudes anteriores. Constitui uma mudança relativamente duradoura no comportamento da pessoa,transferível para novas situações com as quais ela depara (POZO,2002). A aprendizagem,portanto,está associada à noção de mudança e pode ser observada no trabalho quando se compara o desempenho da pessoa antes e depois de um processo de aprendizagem. O desempenho resultante da aplicação de novas competências revela que o indivíduo aprendeu algo novo: mudou sua forma de atuar (FREITAS; BRANDÃO,2005).

Comparando-se os elementos ou as dimensões da competência (conhecimentos, habilidades e atitudes) com proposições de autores de teorias instrucionais e de aprendizagem,é possível identificar relações conceituais entre a aprendizagem e a competência. Pestalozzi (apud LARROYO,I974),por exemplo,idealizou a aprendizagem como o desenvolvimento natural,espontâneo e harmônico das capacidades humanas,que se revelam na tríplice atividade da cabeça,das mãos e do coração (head,hand e heart),isto é,na vida intelectual,psicomotora e moral do indivíduo. Bloom etal. (I973,I979), por sua vez,desenvolveram uma classificação de objetivos educacionais baseada em três domínios: cognitivo (objetivos relacionados à memória e ao desenvolvimento de capacidades intelectuais), psicomotor (objetivos vinculados ao desenvolvimento de habilidades motoras) e afetivo (objetivos que descrevem mudanças de interesses e de valores).

A Figura 2 ilustra a analogia existente entre as chaves da aprendizagem individual (PESTALOZZI apud LARROYO,I974),os domínios dos objetivos educacionais (BLOOM etal.,I973,I979) e as dimensões da competência (DURAND, 2000), explicitando as relações de interdependência entre a aprendizagem e a competência.

FIgURA 2

RELAÇÖES ENTRE A APRENDIZAGEM E A COMPETENCIA

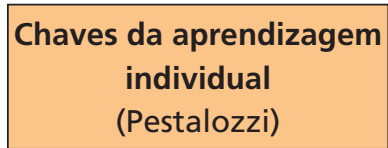

Cabeça (Head)

Mão (Hand)

Coração (Heart)

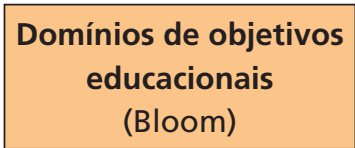

Cognitivo

$>$ Psicomotor

Afetivo

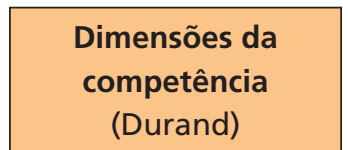

Conhecimentos

Habilidades

Atitudes

Fonte: Brandão etal. (200I). 
Segundo Illeris (2004), o processo de aprendizagem envolve dois ti pos de interação: uma entre o conteúdo (conhecimentos, habilidades e atitudes) e a dinâmica da aprendizagem (motivação,consciência e atenção do aprendiz,entre outros processos); e outra entre o aprendiz e o ambiente em que ele está inserido, que ao mesmo tempo influencia e é influenciado pelo que o indivíduo aprende. Le Boterf (I999) reforça esse entendimento,ressaltando que o desenvolvimento de competências depende fundamentalmente da motivação do indivíduo para aprender,do sistema educacional disponível e de um ambiente de trabalho que estimule a aprendizagem.

É importante às organizações, então,o desenvolvimento de sistemas educacionais não apenas alinhados à sua estratégia, mas também adequados às necessidades de aprendizagem de seus funcionários,o que constitui,segundo Le Boterf (I999),elemento fundamental para conferir efetividade ao processo de desenvolvimento de competências.

Nesse contexto,estão em evidência abordagens denominadas trilhas de aprendizagem (FREITAS; BRANDÃO,2005; BRANDÃO; CARBONE,2004), rotas de aprendizagem para navegação profissional (LE BOTERF,I999) e aprendizagem baseada em competências (GONCZI,I999),que propõem a associação das competências profissionais desejadas pela organização com ações de aprendizagem que permitam o desenvolvimento delas. Essas ações de aprendizagem, por sua vez,não ficam restritas a cursos formais e presenciais. Podem abranger livros, revistas, publicações internas, vídeos e filmes, cursos auto-instrucionais, sites na internet,estágios e sessões de orientação profissional,entre outros,cabendo ao funcionário escolher a ação mais adequada às suas necessidades,gostos e preferências. A escolha da ação de aprendizagem mais apropriada para si faz parte não só da identificação da pessoa com o trabalho,mas também da busca de harmonia entre os interesses pessoais e organizacionais (FREITAS; BRANDÃO,2005).

$\mathrm{Na}$ concepção de abordagens como essas, Le Boterf (I999) ressalta ser importante considerar as diversas possibilidades de aprendizagem existentes, inclusive o próprio ambiente de trabalho,que,segundo ele,constitui o principal espaço educacional dentro das organizações. Para esse autor,qualquer situação de trabalho pode tornar-se uma oportunidade de aprendizagem à medida que constitui um objeto de análise,um momento de reflexão (LE BOTERF,I999). Talvez por isso muitos autores (WARR; DOWNING,2000; HOLMAN etal., 200I; ILLERIS, 2004, entre outros) estejam se dedicando ao estudo de modelos e estratégias de aprendizagem no trabalho.

Sobre o ambiente de trabalho, outro condicionante do desenvolvimento e da expressão de competências profissionais, é importante ressaltar que há evidências empíricas de que aspectos relacionados ao suporte organizacional disponível ao indivíduo,como o apoio oferecido pelo gestor e pelos cole- 
gas, os incentivos e oportunidades de desempenho, e outras propriedades situacionais, afetam a transferência da aprendizagem, ou seja, a expressão de competências no trabalho. Um estudo realizado por Colquittetal. (apud SONNENTAG et al., 2004), por exemplo, identificou forte correlação positiva entre apoio gerencial e transferência da aprendizagem. Williams etal. (apud SONNENTAG etal.,2004), por sua vez, apontam que os profissionais procuram mais por feedback quando seus supervisores manifestam apoio,o que influencia positivamente a aprendizagem e o desempenho. Abbad (I999) também aponta o suporte organizacional como condicionante do desempenho no trabalho. Em seu estudo,essa autora validou uma escala de suporte organizacional à transferência,evidenciando este como um importante preditor do impacto de treinamento no trabalho.

Entre os aspectos do ambiente que afetam a expressão de competências no trabalho,Sonnentag etal. (2004) destacam o arranjo organizacional (oportunidades,reconhecimento,incentivos e recompensas), fatores sociais (apoio gerencial, apoio de colegas e clima organizacional) e tecnologia (processos e instrumentos de trabalho). No que se refere à influência de incentivos sobre o comportamento no trabalho,por exemplo,a pesquisa realizada por McClelland (I985) apontou que o valor atribuído pelas pessoas aos incentivos que recebem prediz o seu desempenho. McClelland (1985) esclarece,ainda,que incentivos não precisam ser necessariamente monetários,pois há estudos que mostram que as pessoas atribuem grande valor a benefícios não-monetários,como "tempo livre" de trabalho e orientação de carreira,entre outros.

Como descrito, para favorecer o desenvolvimento e a expressão de competências no trabalho,as organizações podem atuar tanto sobre componentes disposicionais - promovendo a aprendizagem de conhecimentos, habilidades e atitudes - como sobre fatores situacionais - criando um ambiente que seja estimulador da transferência da aprendizagem para o trabalho. Não obstante os esforços que têm sido realizados, sobretudo no campo teórico,para explicar a natureza da competência e de seus componentes,suas causas e efeitos,muitas questões ainda permanecem sem resposta,sugerindo a necessidade de se realizarem mais investigações empíricas para compreender melhor a competência e seus antecedentes. Isso remete à necessidade de estabelecer uma agenda de pesquisas sobre o tema,o que será sugerido a seguir.

\section{CONSIDERAÇÕES FINAIS}

A noção de competência caracteriza-se como complexa e multifacetada, podendo ser interpretada de diferentes maneiras. Embora esse conceito tenha 
emergido na área de Administração,algumas teorias,pesquisas e proposições de outras áreas de conhecimento,como a Psicologia Social e Organizacional, ajudam a compreender a natureza da competência e de seus componentes.

Como visto neste ensaio, estudos relacionados à atribuição de causa e à aprendizagem, entre outros, podem ser utilizados para interpretar a noção de competência,com base na análise de suas causas e conseqüências.

Embora as investigações e os modelos de atribuição de causa sejam por definição relacionados às causas dos comportamentos, e não às suas conseqüências,os teóricos da atribuição de causa poderiam considerar também os efeitos do comportamento em seus modelos, expandindo a perspectiva da atribuição, conforme sugerido por Vonk (I998). Isso poderia contribuir para a melhor compreensão dos efeitos da competência,isto é,do valor econômico e social gerado em decorrência da expressão de competências no trabalho.

Além disso,considerando o contexto de fragmentação teórica no qual está inserida a noção de competência,é fundamental a realização de mais estudos sobre esse constructo, em especial para verificar empiricamente as relações entre variáveis que são tidas como causas e conseqüências do desempenho ou da expressão de competências no trabalho. Organizações e pesquisadores poderiam,por exemplo,se dedicar a:

a) investigar as efetivas relações entre conhecimentos, habilidades e atitudes, elementos tidos como componentes ou dimensões da competência profissional;

b) identificar estímulos e barreiras ao desenvolvimento e ao compartilhamento de competências no trabalho;

c) analisar como as competências podem mediar as relações entre os estímulos presentes no ambiente organizacional e o comportamento adotado no trabalho;

d) investigar que fatores (disposicionais e situacionais) exercem maior influência sobre o desempenho ou a expressão de competências no trabalho;

e) examinar que estratégias de aprendizagem no trabalho estão mais associadas ao desenvolvimento de competências e à melhoria de desempenho; e

f) identificar em que medida as competências profissionais expressas por pessoas e equi pes de trabalho explicam a variância dos resultados organizacionais.

Tratando-se de estudo sobre um conceito em evidência e cujos pressupostos ainda carecem de investigações empíricas,espera-se que este ensaio tenha oferecido contribuições ao debate teórico em torno do tema,bem como ensejado a realização de pesquisas. 


\section{REFERÊNCIAS}

ABBAD,G. Um modelo integrado de avaliação do impacto do treinamento no trabalho -IMPACT. I999. Tese (Doutorado) -Instituto de Psicologia,Universidade de Brasília,Brasília,I999.

BAHRY,C. P.; BRANDÃO,H. P.; FREITAS,I. A. Efeitos da percepção de suporte à transferência sobre a aplicação de competências no trabalho: o caso dos mestres e doutores do Banco do Brasil. In: ENCONTRO ANUAL DA ASSOCIAÇÃO DOS PROGRAMAS DE PÓS-GRADUAÇÃO EM ADMINISTRAÇÃO -ENANPAD,30.,2006,Salvador. Anais... Salvador: Anpad,2006.

BANDURA,A. Principles of behavior modification. New York: Holt,Rinehartand Winston,I969.

BASTOS,A. V. B. Cognição nas organizações de trabalho. In: ZANELLI,J. C.; BORGES-ANDRADE, J. E.; BASTOS,A. V. B. (Org.). Psicologia,organizações e trabalho no Brasil. Porto Alegre: Artmed, 2004 .

BLOOM,B. S.; KRATHWOHL,D. R.; MASIA,B. B. Taxonomia de objetivos educacionais: domínio afetivo. Porto Alegre: Globo,I973.

BLOOM,B. S. etal. Taxonomia de objetivos educacionais: domínio cognitivo. Porto Alegre: Globo, I979.

BOYATZIS,R. E. The competent management: a model for effective performance. New York: John Wiley,I982.

BITENCOURT,C. C. A gestão de competências gerenciais e a contribuição da aprendizagem organizacional. Revista de Administração de Empresas,v. 44,n. I,p. 58-69,2004.

BRANDÃO,H. P. Competências no trabalho e nas organizações: uma análise da produção científica brasileira. In: ENCONTRO ANUAL DA ASSOCIAÇÃO DOS PROGRAMAS DE PÓS-GRADUAÇÃO EM ADMINISTRAÇÃO - ENANPAD,30.,2006, Salvador. Anais... Salvador: ANPAD, 2006.

BRANDÃO,H. P.; CARBONE,P. P. A web como instrumento para construção de trilhas de aprendizagem. In: BAYMA,F. (Org.). Educação corporativa: desenvolvendo e gerenciando competências. São Paulo: Pearson Prentice-Hall,2004.

BRANDÃO,H. P.; GUIMARÃES,T. A. Gestão de competências e gestão de desempenho. In: WOOD JÚNIOR.,T. (Org.). Gestão empresarial: o fator humano. São Paulo: Atlas,2002.

BRANDÃO,H. P.; GUIMARÃES,T. A.; BORGES-ANDRADE,J. E. Professional competencies to achieve top standards of quality in retail banking services. In: THE BUSINESS ASSOCIATION OF LATIN AMERICAN STUDIES -BALAS (Org.). Proceendings of the XVII BALAS Annual Conference. San Diego,Estados Unidos: Balas,200I.

CARBONE,P. P. etal. Gestão por competências e gestão do conhecimento. Rio de Janeiro: Fundação Getulio Vargas,2005. (Gestão de pessoas).

CASEY,C. The changing contexts of work. In: BOUD,D.; GARRICK,J. (Org.). Understanding learning at work. London: Routledge,I999.

DAVENPORT,T. H.; PRUSAK,L. Working knowledge: how organizations manage whatthey know. Boston: Harvard Business School Press,I998.

DAVIS,S.; BOTKIN,J. The coming of knowledge-based business. Harvard Business Review,Boston, p. I65-I70,I994.

DAVIS,K.; NEWSTROM,J. Comportamento humano no trabalho: uma abordagem psicológica. São Paulo: Pioneira Thomson Learning,I992. 
DURAND,T. L’alchimie de la compétence. Revue Française de Gestion,v. I27,p. 84-I02,2000.

DUTRA,J. S. Competências: conceitos e instrumentos para a gestão de pessoas na empresa moderna. São Paulo: Atlas,2004.

FLEURY,A.; FLEURY,M. T. Estratégias empresariais e formação de competências: um quebra-cabeça caleidoscópico da indústria brasileira. São Paulo: Atlas,200I.

FREITAS,I. A.; BRANDÃO,H. P. Trilhas de aprendizagem como estratégia para desenvolvimento de competências. In: $29^{\circ}$ ENCONTRO ANUAL DA ASSOCIAÇÃO DOS PROGRAMAS DE PÓSGRADUAÇÃO EM ADMINISTRAÇÃO -ENANPAD,2005. Anais... Brasília: Anpad,2005.

GAGNÉ,R. M.; BRIGGS,L. J.; WAGER,W. W. Principles of instructional design. Orlando: Holt, Rinehartand Winston,I988.

GILBERT,T. F. Human competence: engineering worthy performance. New York: McGraw-Hill Book Company,I978.

GONCZI,A. Competency-based learning: a dubious past-an assured future? In: BOUD,D.; GARRICK,J. (Org.). Understanding learning at work. London: Routledge,I999.

HARACKIEWICZ,J.; SANSONE,C.; MANDERLINK,G. Competence, achievement orientation, and intrinsic motivation: a process analysis. Journal of Personality and Social Psychology,v. 48,n. 2, p. 493-508,I985.

HEENE,A.; SANCHEZ,R. Competence based strategic management. Chichester: John Wiley \& Sons, I997.

HEIDER,F. The psychology of interpersonal relations. New York: John Wiley \& Sons,I958.

HOLMAN,D.; EPITROPAKI,O.; FERNIE,S. Understanding learning strategies in the workplace: a factor analytic investigation. Journal of Occupational and Organizational Psychology,v. 74,p. 67568I,200I.

ILLERIS,K. A model for learning in working life. The Journal of Workplace Learning. v. I6,n. 8, p. 43I-44I,2004.

ISAMBERT-JAMATI,V. O apelo à noção de competência na revista L'orientation scolaire et profissionelle: da sua criação aos dias de hoje. In: ROPÉ,F.; TANGUY,L. (Org.). Saberes e competências: o uso de tais noções na escola e na empresa. Campinas: Papirus,I997.

LARROYO,F. História geral da pedagogia. São Paulo: Mestre Jou,I974.

LE BOTERF,G. Competénce et navigation professionnelle. Paris: Éditions d'Organisation,I999.

MARTIN-BARÓ,I. Acción e ideologia: psicologia social de centroamérica. San Salvador: UCA, I985.

MCCLELLAND,D. Testing for competence rather than intelligence. American Psychologist,v. 28, n. I,p. I-I4,I973.

. How motives, skills, and values determine whatpeople do. American Psychologist,v. 40,

n. 7,p. 8I2-825,I985.

MCLAGAN,P. A. Competencies: the nextgeneration. Training \& Development,v. 5I,n. 5,p. 40-47, I997.

POZO,J. I. Aprendizes e mestres: a nova cultura da aprendizagem. Porto Alegre: Artmed,2002.

PRAHALAD,C. K.; HAMEL,G. The core competence of the corporation. Harvard Business Review, v. 68,n. 3,p. 79-93,I990.

PRIMI,R. etal. Competências e habilidades cognitivas: diferentes definições dos mesmos construtos. Revista Psicologia: Teoria e Pesquisa,v. I7,n. 2,p. I5I-I59,200I. 
REEDER,G. D. etal. Dispositional attribuition: multiple inferences aboutmotive-related traits. Journal of Personality and Social Psychology,v. 86,n. 4,p. 530-544,2004.

SANCHEZ,R. Managing articulated knowledge in competence-based competition. In: SANCHEZ, R.; HEENE,A. (Org.). Strategic learning and knowledge management. Chichester: John Wiley \& Sons, I997.

SANSONE,C. A question of competence: the effects of competence and task feedback on intrinsic interest. Journal of Personality and Social Psychology, v. 51,n. 5,p. 918-931,I986.

SONNENTAG,S.; NIESSEN,C.; OHLY,S. Learning atwork: training and development. International Review of Industrial and Organizational Psychology,v. I9,p. 249-289,2004.

VONK,R. Effects of behavioral causes and consequences on person judgments. Personality \& Social Psychology Bulletin,v. 24,n. I0,p. I.065-1.075,1998.

VONK,R.; KONST,D. Effects of beravioral causes and consequence on perceived competence of leadears and subordinates. Journal of Applied Social Psychology,v. 33,n. 8,p. I.684-I.692,2003.

WARR,P.; DOWNING,J. Learning strategies,learning anxiety and knowledge acquisition. British Journal of Psychology,v. 9I,p. 3II-333,2000.

ZARIFIAN,P. Objectif compétence: pour une nouvelle logique. Paris: Editions Liaisons,I999.

\section{TRAMITAÇÃO}

Recebido em $24 / 7 / 2006$

Aprovado em $30 / 10 / 2006$ 
Copyright of Revista de Administração Mackenzie is the property of Universidade Presbiteriana Mackenzie, RAM-Revista de Administracao Mackenzie and its content may not be copied or emailed to multiple sites or posted to a listserv without the copyright holder's express written permission. However, users may print, download, or email articles for individual use. 